\title{
Encounters in the Archive - Capturing the experience of the interaction between the artist and the archive
}

\author{
Donatella Barbieri \\ London College of Fashion / Victoria and Albert Museum \\ United Kingdom \\ d.barbieri@vam.ac.uk
}

\section{INTRODUCTION}

Having been granted access to the archive and to objects that are seldom seen outside their acid free boxes, this presentation explores ways in which phenomenological approaches to the process of filming and editing can capture the experience of perception as a springboard for the creative impetus.

Using the film 'Encounters in the Archive' shot by Netia Jones (http://www.lightmap.net) at Blythe House, in the Victoria and Albert Museum Theatre and Performance Archive, this paper considers responses to both the experience of the space of the archive, 'old' costumes and objects of performance, and the interaction of the archive with a group of six selected artists, theorists, and designers.

Through this presentation, I engage with notions of perception, of performativity of space, form, and materials, as manipulated by the camera, in the filming and the editing process of the six separate encounters with the hidden objects. 